\title{
Una evaluación clínica estandarizada en el consultorio tiene moderada exactitud para el diagnóstico etiológico de vaginitis
}

office based standarized clinical evaluation has moderate accuracy for etiologic vaginitis diagnosis

Lowe N y col. Obstetrics \& Gynecology. 2009 Enero; 113(1):89-95

\section{Objetivo}

Estimar la exactitud de una evaluación clínica estandarizada realizada en el consultorio (ECEC) para el diagnóstico etiológico de las tres causas más frecuentes de vaginitis (vaginosis bacteriana, tricomoniásica y candidiásica).

\section{Diseño, lugar y pacientes}

Estudio de corte trasversal realizado en cuatro clínicas de los Estados Unidos que comparó en forma ciega la ECEC con la detección por ADN. Fueron incluidas 535 mujeres adultas con síntomas de vaginitis y fueron excluidas aquellas que estuvieran menstruando o que hubiesen tenido relaciones sexuales en las últimas 24 horas.

\section{Descripción de las pruebas diagnósticas}

La ECEC fue realizada por enfermeras y consistió en interrogatorio, especuloscopía, determinación del pH vaginal, test de amina y observación de preparados húmedos en el microscopio. La prueba de referencia fue la detección de ADN para Gardnerella vaginalis, Trichomonas vaginalis, y Cándida en el fluido vaginal.

\section{Medición de resultados principales}

Sensibilidad, especificidad, exactitud diagnóstica, valores predictivos $^{*}$ y razones de probabilidad ${ }^{\star}$ positivos y negativos de la ECEC.

\section{Resultados principales}

La tabla 1 resume las principales características operativas de la ECEC.

Tabla 1: características operativas de la evaluación clínica estandarizada para diagnóstico de vaginitis.

\begin{tabular}{|c|c|c|c|c|c|c|}
\hline & \multirow{2}{*}{$\begin{array}{l}\text { Sensibilidad } \\
\text { (IC 95\%) }\end{array}$} & \multirow{2}{*}{$\begin{array}{l}\text { Especificidad } \\
\text { (IC 95\%) }\end{array}$} & \multicolumn{2}{|c|}{ Valor predictivo (IC 95\%) } & \multicolumn{2}{|c|}{ Coeficiente de probabilidad (LR) } \\
\hline & & & Positivo & Negativo & Positivo & Negativo \\
\hline $\begin{array}{c}\text { Vaginitis } \\
\text { tricomoniásica }\end{array}$ & $\begin{array}{c}84,6 \\
(64,3 \text { a } 95)\end{array}$ & $\begin{array}{c}99,6 \\
(98,4 \text { a } 99,9)\end{array}$ & $\begin{array}{c}91,7 \\
(71,5 \text { a } 98,5)\end{array}$ & $\begin{array}{c}99,2 \\
(97,9 \text { a } 99,7)\end{array}$ & 211,5 & 0,15 \\
\hline $\begin{array}{l}\text { Vaginosis } \\
\text { bacteriana }\end{array}$ & $\begin{array}{c}80,8 \\
(75,9 \text { a } 84,9)\end{array}$ & $\begin{array}{c}70 \\
(73,4 \text { a } 75,8)\end{array}$ & $\begin{array}{c}79 \\
(74 \text { a 83,3) }\end{array}$ & $\begin{array}{c}72,2 \\
(65,7 \text { a } 78)\end{array}$ & 2,69 & 0,27 \\
\hline $\begin{array}{c}\text { Vaginitis } \\
\text { candidiasica }\end{array}$ & $\begin{array}{c}83,8 \\
(76,6 \text { a } 89,1)\end{array}$ & $\begin{array}{c}84,8 \\
(80,7 \text { a } 88,1)\end{array}$ & $\begin{array}{c}67,8 \\
(60,4 \text { a } 74,4)\end{array}$ & $\begin{array}{c}93,2 \\
(89,9 \text { a } 95,5)\end{array}$ & 5,51 & 0,19 \\
\hline
\end{tabular}

La evaluación clínica estandarizada incluyo: interrogatorio, especuloscopía, determinación del pH vaginal, test de amina y observación de preparados húmedos en el microscopio.

\section{Conclusiones}

Comparado con la prueba de ADN estándar, la ECEC tiene una sensibilidad del 81 a $85 \%$ y una especificidad del 70 a $99 \%$ para vaginitis bacteriana, candidiásica y tricomoniásica. Aún bajo condiciones de investigación clínica que brindaron el tiempo y los materiales suficientes para realizar una profunda y estandarizada evaluación clínica, el diagnóstico y el posterior tratamiento de las causas más frecuentes de vaginitis siguen siendo dificultosos.

Palabras claves: vaginitis, prueba de ADN, diagnóstico clínico. Key words: vaginitis, DNA test, clinical diagnosis. Fuente de financiamiento: No referida

\section{Comentario}

La vaginitis representa cerca del $10 \%$ de los motivos de consulta en atención primaria, siendo una de las causas más frecuentes de consulta ginecológica'. Sus síntomas son el cambio en la consistencia y el color del flujo, el prurito, el ardor, el mal olor, la disuria y la dispareunia.

La vaginitis puede deberse a causas infecciosas, hormonales o por irritantes locales siendo en más de la mitad de los casos de origen infeccioso, en los que la transmisión sexual ocupa un papel importante ${ }^{2}$. El $90 \%$ de las vaginitis infecciosas están causadas por cándida, tricomonas y vaginosis bacteriana'. En esta cohorte, quienes realizaron la evaluación clínica estandarizada, contaron con el tiempo y los materiales necesarios, situación que habitualmente no ocurre en la práctica diaria. La pregunta que surge de esta observación es ¿qué exactitud tendría el diagnóstico clínico que utilizamos habitualmente en nuestra práctica en la que el manejo de estas situaciones es bastante más empírico?

Si bien este estudio demostró que la exactitud de este tipo de
ECEC fue moderada y variable, la alta tasa de resolución de los síntomas $(94 \%)$ con cualquier tratamiento instituido podría restarle importancia a un diagnóstico exacto en la mayoría de los casos.

\section{Conclusiones de la comentadora}

Si bien el estudio evaluó la exactitud de una ECEC bajo condiciones de tiempo y material adecuados, no respondió la pregunta de lo que sucede con el manejo empírico de la vaginitis en la práctica habitual. Sería útil realizar un ensayo clínico controlado y aleatorizado que comparara la aplicación del diagnóstico clínico en la práctica usual, comparado con el manejo empírico, midiendo resultados relevantes para las pacientes tales como medidas de satisfacción, y teniendo en cuenta la elevada tasa de resolución de las vaginitis cualquiera sea el tratamiento instituido.

Ver glosario*

Mercedes Mutchinick [ Servicio de Medicina Familiar y Preventiva del Hospital Italiano de Buenos Aires. mercedes.mutchinik@ hospitalitaliano.org.ar ]

Mutchinick M. El diagnóstico clínico tiene moderada exactitud en las vaginitis más frecuentes. Evid Act Pract Ambul. 13(1):11. Ene-Mar, 2010. Comentado de: Lowe N y col. Accuracy of the Clinical Diagnosis of Vaginitis Compared With a DNA Probe Laboratory Standard. Obstetrics \& Gynecology. 2009 Enero; 113(1):89-95. PMID 19104364.

\section{Referencias}

1.Kopitowski K. Vaginitis. Capítulo 79. En: "Medicina Familiar y Practica Ambulatoria". Editores Rubinstein A. Terrasa S, Carrete P. Editorial Médica Panamericana, Marzo de 2001. pp 652.

2. López Alvarez X y col. Vuvovaginitis. [publicación en línea]. Disponible desde Internet en: <http://www. fisterra.com/guias2/vaginitis.asp> [con acceso el 08-06-09]. 